\title{
CDKN1A and FANCD2 are potential oncotargets in Burkitt lymphoma and multiple myeloma
}

\author{
Seong-Su Han ${ }^{1 \dagger}$, Van S Tompkins ${ }^{2 \dagger}$, Dong-Ju Son ${ }^{5 \dagger}$, Sangwoo Han ${ }^{3}$, Hwakyung Yun ${ }^{6}$, Natalie L Kamberos ${ }^{1}$, \\ Casey L Dehoedt ${ }^{2}$, Chunyan Gu ${ }^{2}$, Carol Holman ${ }^{2}$, Guido Tricot ${ }^{4}$, Fenghuang Zhan ${ }^{4}$ and Siegfried Janz ${ }^{2 *}$
}

\begin{abstract}
Background: Comparative genetic and biological studies on malignant tumor counterparts in human beings and laboratory mice may be powerful gene discovery tools for blood cancers, including neoplasms of mature B-lymphocytes and plasma cells such as Burkitt lymphoma (BL) and multiple myeloma (MM).

Methods: We used EMSA to detect constitutive NF-KB/STAT3 activity in BL- and MM-like neoplasms that spontaneously developed in single-transgenic IL6 (interleukin-6) or MYC (c-Myc) mice, or in double-transgenic IL6MYC mice. qPCR measurements and analysis of clinical BL and MM datasets were employed to validate candidate NF-KB/STAT3 target genes.

Results: GPCR demonstrated that IL6- and/or MYC-dependent neoplasms in mice invariably contain elevated mRNA levels of the NF-kB target genes, Cdkn1a and Fancd2. Clinical studies on human CDKN1A, which encodes the cell cycle inhibitor and tumor suppressor p21, revealed that high p21 message predicts poor therapy response and survival in BL patients. Similarly, up-regulation of FANCD2, which encodes a key member of the Fanconi anemia and breast cancer pathway of DNA repair, was associated with poor outcome of patients with MM, particularly those with high-risk disease.

Conclusions: Our findings suggest that CDKN1A and FANCD2 are potential oncotargets in BL and MM, respectively. Additionally, the IL-6- and/or MYC-driven mouse models of human BL and MM used in this study may lend themselves to the biological validation of CDKN1A and FANCD2 as molecular targets for new approaches to cancer therapy and prevention.
\end{abstract}

Keywords: p21 tumor suppressor, Fanconi anemia and breast cancer DNA damage repair, Genetically engineered mouse models of human cancer, Molecularly targeted cancer therapy

\section{Background}

Comparative histopathologic, genomic and biological analyses of malignant tumor counterparts in humans and mice afford a powerful approach to improve our understanding of evolutionarily conserved signaling networks that underlie oncogenesis and are thus of great significance for public health. An important objective of cross-species analysis of neoplastic development is the discovery of concordantly deregulated genes that play an important role in tumor development and progression, response to therapy, acquisition of drug resistance, and clinical outcome. Proteinencoding genes that are overexpressed in cancer cells and

\footnotetext{
* Correspondence: siegfried-janz@uiowa.edu

'Equal contributors

2Department of Pathology, University of lowa Carver College of Medicine, lowa City, IA, USA

Full list of author information is available at the end of the article
}

potentially inhibitable by small compounds are of particular interest to that end, because they are actionable in terms of molecularly targeted drug development. Here, we take advantage of MYC- [1], IL6- [2] and IL6MYC-transgenic (Tg) mice $[3,4]$ that recapitulate important features of human Burkitt lymphoma (BL) or multiple myeloma (MM) to uncover up-regulated candidate cancer genes that might have been overlooked in other studies. We show that MYC and/ or IL-6-driven B cell and plasma cell tumors of mice exhibit constitutive NF- $\mathrm{kB}$ activity that leads to overexpression of NF-kB target genes such as Cdkn1a and Fancd2. These genes encode the well-established tumor suppressor, p21, and a key member of the Fanconi anemia/breast cancer DNA damage repair pathway, respectively. Interrogation of a well-annotated clinical dataset $(\mathrm{n}=351)$ suggested that FANCD2 is a MM gene. Likewise, in vitro studies on tumor 
cell lines and clinical outcome results indicated that CDKN1A may be a BL oncogene. Although additional work is warranted before the utility of CDKN1A and FANCD2 as molecular targets for drug development can be fully evaluated, our study underlines the value of comparative oncogenomic and molecular genetic research on human-mouse cancer counterparts for developing new approaches to cancer therapy and prevention.

\section{Results}

\section{Constitutive NF-KB and STAT3 activity in IL-6 and/or} MYC-driven $B$ cell and plasma cell tumors in mice

Because NF- $\kappa B$ and STAT3 are important regulators of B-lineage neoplasms in humans and mice, we used EMSA to examine NF- $\mathrm{kB}$ and STAT3 activity in MACSpurified $\mathrm{B}_{220^{+}}$samples from 19 primary tumors obtained from single-transgenic IL-6 $(\mathrm{n}=6)$ or MYC $(\mathrm{n}=5)$ mice and double-transgenic IL6MYC $(\mathrm{n}=8)$ mice (Figure 1). Compared to normal $\mathrm{B}_{2} 20^{+}$splenocytes used as control, all tumor samples contained a significantly elevated DNAbinding activity of both transcription factors (Figure 2A and B). To ascertain the subunit composition of NF-kB dimers, we performed super-shift assays using nuclear extracts (NEs) from tumor cells isolated from enlarged spleens of IL6MYC mice. We included antibodies (Abs) to all 5 NF-kB subunits (Figure 2C) and observed notable shifts for three: p50 (lane 2), p65 (lane 3) and c-Rel (lane 4). Ab to RelB caused only a faint shift (lane 6) and p52 seemed to be uninvolved (lane 5). Similar to our previous findings on the MYC-dependent mouse lymphoma cell line $\mathrm{iMyc}^{\mathrm{E \mu}}$ [5], $\mathrm{Ab}$ to 550 shifted two NF-kB-specific bands to higher molecular-weight positions on EMSA gels, whereas Ab to $\mathrm{p} 65$ or c-Rel shifted only the upper or lower band, respectively. Both activated STAT3, pSTA3, and acetyltransferase $\mathrm{p} 300$, a positive regulator of NF- $\mathrm{kB} / \mathrm{STAT} 3$ signaling [6,7], were physically associated with NF-kB in IL6MYC tumor cells (lanes 7 and 8). Next, we confirmed these findings with the assistance of STAT3 super-shift assays, using the same NEs as in panel $C$ (Figure 2D). We found that three NF-kB subunits (p50, lane 2; p65, lane 3; c-Rel, lane 4), pStat3 (lane 7) and p300 (lane 8) participated in protein complexes that were able to bind a canonical STAT3 DNA recognition sequence. The results presented in Figure 2 suggested that the constitutive NF- $\mathrm{kB}$ activity in IL6MYC tumors is comprised of both p50 homo and p50 hetero (with p65 and c-Rel) dimers that are further associated with p300 and pSTAT3. While the association with the former has not yet been reported to the best of our knowledge, the latter finding is in agreement with reports on the physical association of STAT3 and NF- $\mathrm{kB}$ in various cell types [8] including MYC-transgenic Blymphocytes [5].

\section{Up-regulation of Cdkn1a and Fancd2 in mouse tumor cells}

qPCR analysis of RNA from tumor cells isolated from seven different IL-6- and/or MYC-induced neoplasms included in Figure $2 \mathrm{~A}$ and $\mathrm{B}$ demonstrated that three well-established NF- $\mathrm{BB}$ target genes were consistently up-regulated in this sample: Cdkn1a, a target of the tumor-suppressor p53, and two DNA repair genes, Fancd2 and Xcrcc6 (Figure 3A). Mean Cdkn1a message in tumor cells was 11.1-fold elevated compared to normal B cells (standard deviation $8.69 ; p=0.0169$ by Mann-Whitney), whereas expression of Trp53 (encodes p53) was down regulated $(0.614 \pm 0.219 ; p=0.0006)$. Fancd 2 and Xcrcc 6 expression was increased by a factor of $4.27 \pm 2.08 \quad(p=0.0006)$ and $1.97 \pm 1.20 \quad(p=0.0169)$, respectively. Median expression values of the 4 genes varied significantly using Kruskall-Wallis test $(p=$ 0.0006). Because the small amounts of tumor RNA available were insufficient to evaluate additional genes of interest, we prepared RNA from another tumor set $(\mathrm{n}=$ 21) obtained from an independent cohort of IL6MYC mice. Continuing with the qPCR analysis, we first confirmed the changes presented in Figure 3A (results not shown) and then showed that the genes encoding aurora kinase A (Aurka) and the germinal center B cell master transcription factor Blimp-1 (Prdm1) were up-regulated in tumor cells, whereas expression of Irf1 (interferon regulatory factor 1, Egr1 (early growth response 1) and Bcl2 (B cell leukemia 2) was decreased (Figure 3B). The differences in gene expression were highly significant for each gene individually (compared to normal B cells; $p<$ 0.0001 , Mann Whitney) and considered as a set $(p<$ 0.0001, Kruskall-Wallis). Cdkn1a, Fancd2, Xcrcc6, Aurka and Prdm1 are drug-inhibitable overexpressed proteinencoding genes that might be of interest for the development of molecularly targeted interventions.

\section{CDKN1A is a candidate oncogene in human Burkitt lymphoma (BL)}

$C d k n 1 a$ was of special interest to us because (1) evidence has emerged that p21 may promote tumor development despite its more widely known role as cell cycle inhibitor and tumor suppressor [9], (2) the p21 and p53 message levels presented in Figure 3A were in line with findings in oral squamous cell carcinoma [10], head and neck cancer [11] and breast cancer [12] indicating that expression of p21 may be independent of p53, (3) $\mathrm{mCD} 40-\mathrm{LMP} 1 / \mathrm{iMyc}^{\mathrm{E} \mu}$-driven BL-like neoplasms in mice contain elevated levels of p21 mRNA [13] and (4) findings indicate that RelB, which is involved in IL6MYCdependent NF- $\mathrm{kB}$ activation as shown in Figure $2 \mathrm{C}$, may be a positive regulator of p21's oncogenic function [14]. To follow up on the possibility that p21 has oncogenic properties in neoplasms of mature B-lymphocytes, and 


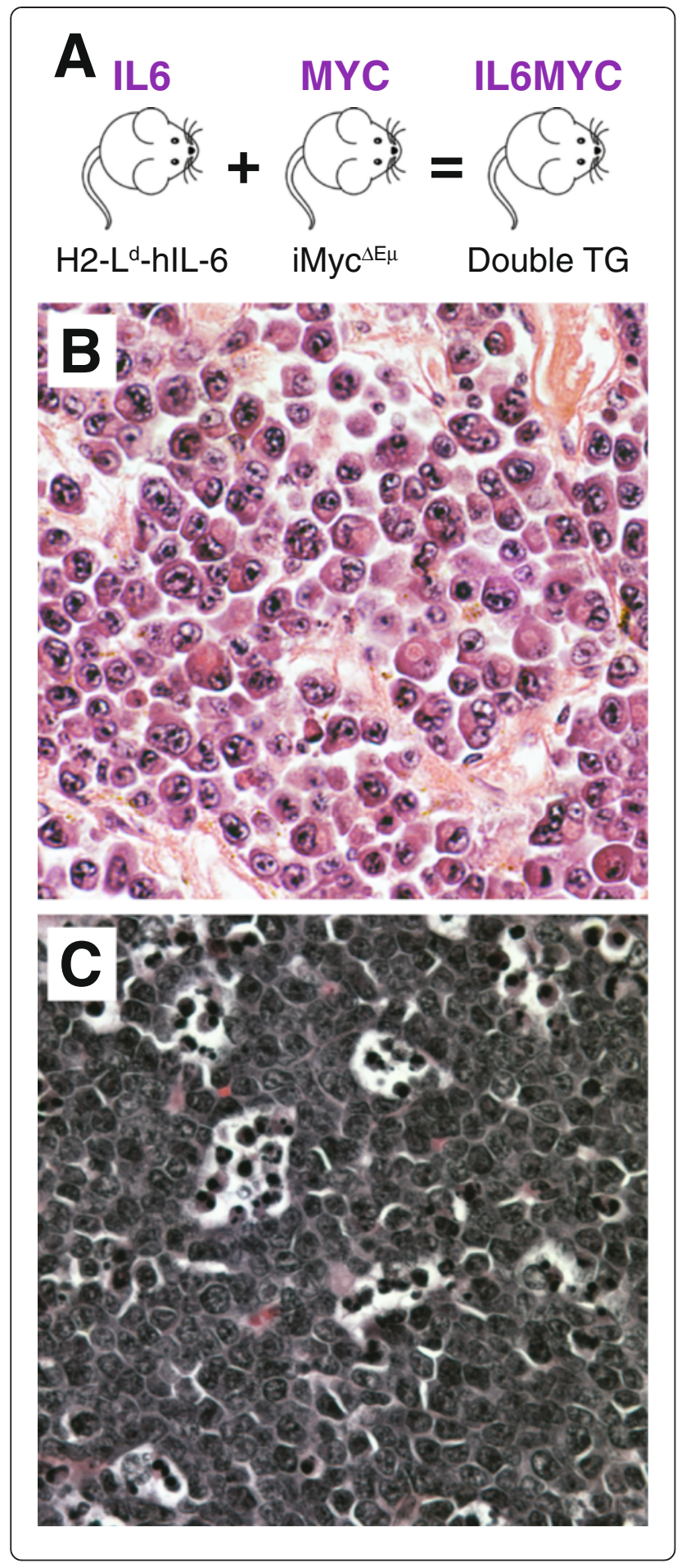

Figure $1 \mathrm{MYC}$ and/or IL-6 driven mouse models of human Burkitt lymphoma (BL) and multiple myeloma (MM). (A) Overview of transgenic (Tg) mice used in this study. IL6 mice harbor a widely expressed human interleukin-6 transgene designated H2-L $L^{d}-h \mid L 6$ [40,41]. MYC mice contain a mouse Myc (c-myc) cDNA transgene that has been inserted in the immunoglobulin heavy-chain locus with the help of gene targeting in embryonic stem cells [42]. IL6MYC mice were generated by intercrossing homozygous-Tg MYC mice and heterozygous-Tg IL6 mice, followed by selection of double-Tg offspring. All mice were on the genetic background of BALB/C (C). (B) Photomicrograph of a representative histologic section of the type of myeloma-like plasma cell tumor that arises consistently in both IL6 and IL6MYC mice (H\&E, original

magnification 40x). Compared to IL6 mice, tumor onset is shorter and tumor incidence is higher in IL6MYC mice. (C) Representative tissue section of the main type of tumors observed in MYC mice: Burkitt-like lymphoblastic B-cell lymphoma that exhibits the typical "starry sky" morphology due to tingible body macrophages that engulf apoptotic tumor cells ( $H \& E$, original magnification 40x).

to evaluate the clinical significance, if any, of up-regulation of $C D K N 1 A$, we interrogated publicly available gene expression profiles of human non-Hodgkin lymphomas and MM. The dataset of Dave et al. [15] (GSE4732) was most helpful because (1) it permitted us to examine overall survival as a function of CDKN1A expression, (2) it included only cases of $\mathrm{BL}$ that had been validated using molecular signatures and (3) survival data was available for a sufficient number of patients $(\mathrm{n}=51)$. We stratified the patients into 2 groups according to high and low CDKN1A expression at diagnosis (using the median level of p21 as cut-off), generated a Kaplan-Meier plot (Figure 4A, left) and found that p21 High patients had a significantly worse outcome $(p=0.0126)$ compared with their p21 ${ }^{\text {Low }}$ counterparts. Next, we determined whether the same held true when patients were first stratified according to treatment, which was reported for 33 of $51(65 \%)$ cases. Indeed, p21 ${ }^{\text {High }}$ patients receiving either a CHOP-like or even more intensive treatment regimen (INT) fared worse than the p21 ${ }^{\text {Low }}$ group ((Figure 4A, right). Unlike BL, survival of p21 expression-stratified DLBCL patients in the Dave et al. study was not different (Additional file 1: Figure S1). These results are consistent with an oncogenic role for $\mathrm{p} 21$ in $\mathrm{BL}$ and suggest that $\mathrm{p} 21$ expression is a marker of high-risk disease.

\section{Induction of CDKN1A in the course of a drug-induced} stress response in BL cells

The availability of representative tumor cell lines afforded an opportunity to examine the cancer cell-autonomous properties of p21 in human BL in greater depth. We selected 5 independent cell lines, 3 of which are infected with Epstein Barr virus (EBV) and thus express the virus-encoded oncoprotein LMP1: Daudi, Raji and Jiyoye. Two cell lines, DG75 and Ramos, do not harbor EBV (Figure 4B, bottom). Mouse Hal2G1 tumor cells, which carry the mCD40-LMP1 and $\mathrm{iMyc}^{\mathrm{E} \mu}$ transgenes [13], were included for comparison. EBV ${ }^{+}$ BL cells contained increased CDKN1A mRNA compared 

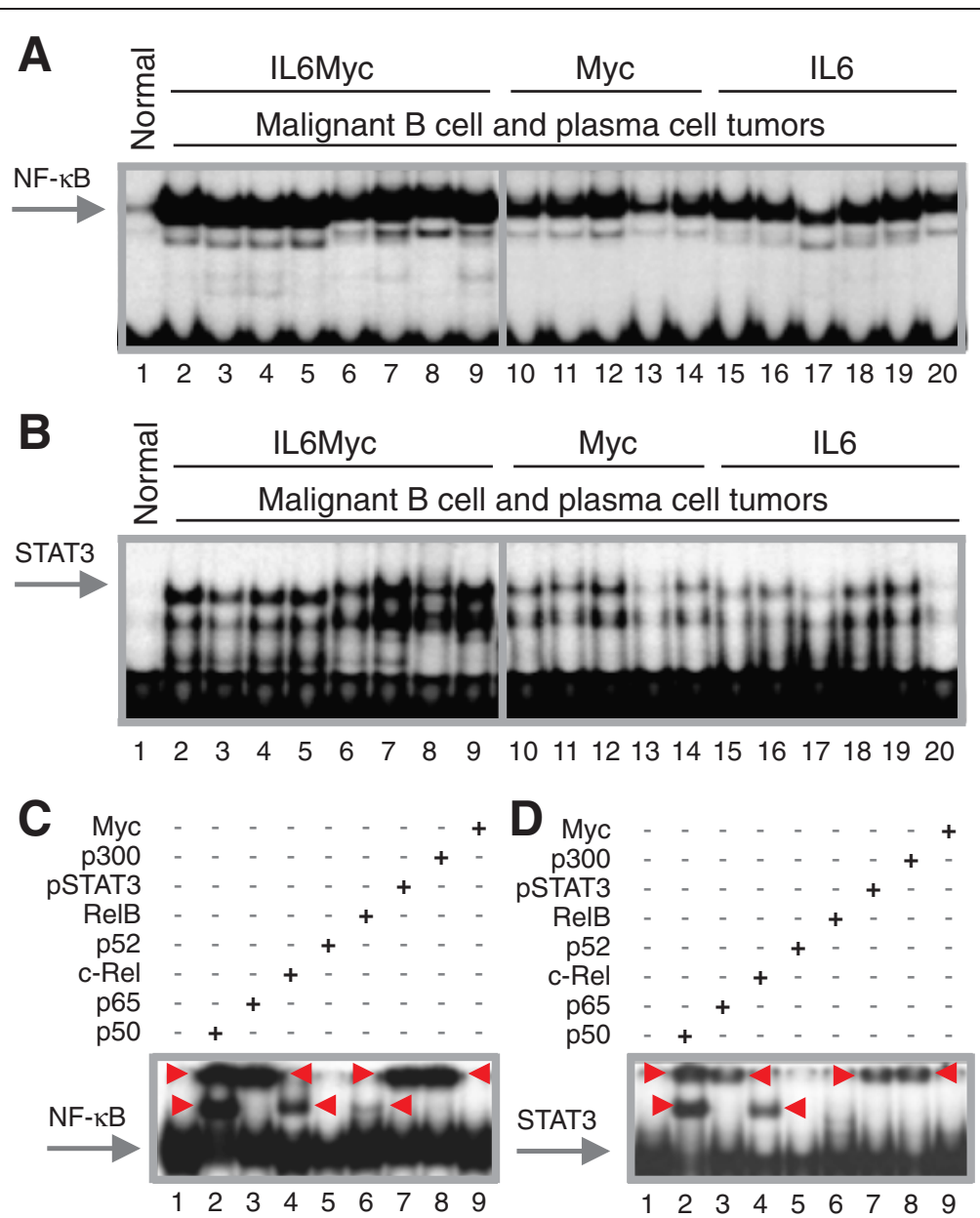

Figure 2 Constitutive activation of NF-KB/Stat3 signaling in malignant B cells and plasma cells of MYC- and/or IL-6-transgenic mice. (A) EMSA result indicating high levels of NF-KB DNA-binding activity in BL-like lymphomas and MM-like plasma cell tumors that developed in double-transgenic IL6MYC mice (lanes 2-9) or single-transgenic MYC (lanes 10-14) or IL6 mice (lanes 15-20). Normal B cells (lane 1) were included as control. (B) EMSA result demonstrating high levels of Stat3DNA-binding activity in the same samples used in panel A. (C) EMSA super-shifts indicating both involvement of p50, p65, c-Rel and, to a lesser extent, RelB in NF-kB activation and physical association of NF-kB proteins with Stat3 and p300. Red arrowheads denote shifted bands. In lanes 2-8, NE (10 $\mu \mathrm{g}$ ) was incubated with $2 \mu \mathrm{g}$ of one of the Abs to NF-kB, pStat3 or p300 indicated above the gel image. Antibody to Myc (lane 9) or omission of Ab (lane 1) were used as controls. Red arrowheads denote shifts. (D) EMSA super-shifts suggesting physical association of NF-KB with pStat3 and p300. Red arrowheads, shifted bands; lanes 2-8, Abs to NF-kB, pStat3 or p300; lanes 1 and 9, controls.

to $\mathrm{EBV}^{-} \mathrm{BL}$ cells (Figure 4B, top), whereas TP53 message (Figure 4B, center) and p53 DNA-binding activity (Figure 4C) were consistently low irrespective of EBV/ LMP1 status. Next we measured CDKN1A expression under conditions of drug-induced stress imposed by treatment of cells with the cancer-inhibiting agent, piperlongumine (PL). In agreement with our previous finding that PL kills human BL and mouse BL-like cells by virtue of a mechanism that includes inhibition of NF$\kappa \mathrm{B}[13,16]$, we found that PL kills 3 of $3 \mathrm{BL}$ lines with similar efficacy (Figure 4D, top). PL-dependent induction of both CDKN1A (Figure 4D, center) and p53 DNA binding activity (Figure 4D, bottom) was more robust in $\mathrm{EBV}^{-}$DG75 cells than in EBV ${ }^{+}$Daudi and Raji cells, but a larger study is warranted to decide whether this is truly associated with EBV/LMP1 status or caused by coincidence. Be this as it may, the results described above implicate the activation of the $\mathrm{p} 53 / \mathrm{p} 21$ pathway in the PL-dependent stress response in BL cells.

\section{FANCD2 is a candidate multiple myeloma (MM) gene}

Next, we focused on another candidate gene included in Figure 3, FANCD2, because the analysis of a clinically annotated MM dataset for which Affymetrix-based gene expression results were available suggested that this gene may be important for myeloma. Figure 5A depicts the levels of FANCD2 in 351 patients with newly diagnosed myeloma, according to increasing gene expression. The mean FANCD2 mRNA level in myeloma cells (351 \pm $268, \mathrm{n}=351$ ) was 4.3 -fold higher than in normal plasma 


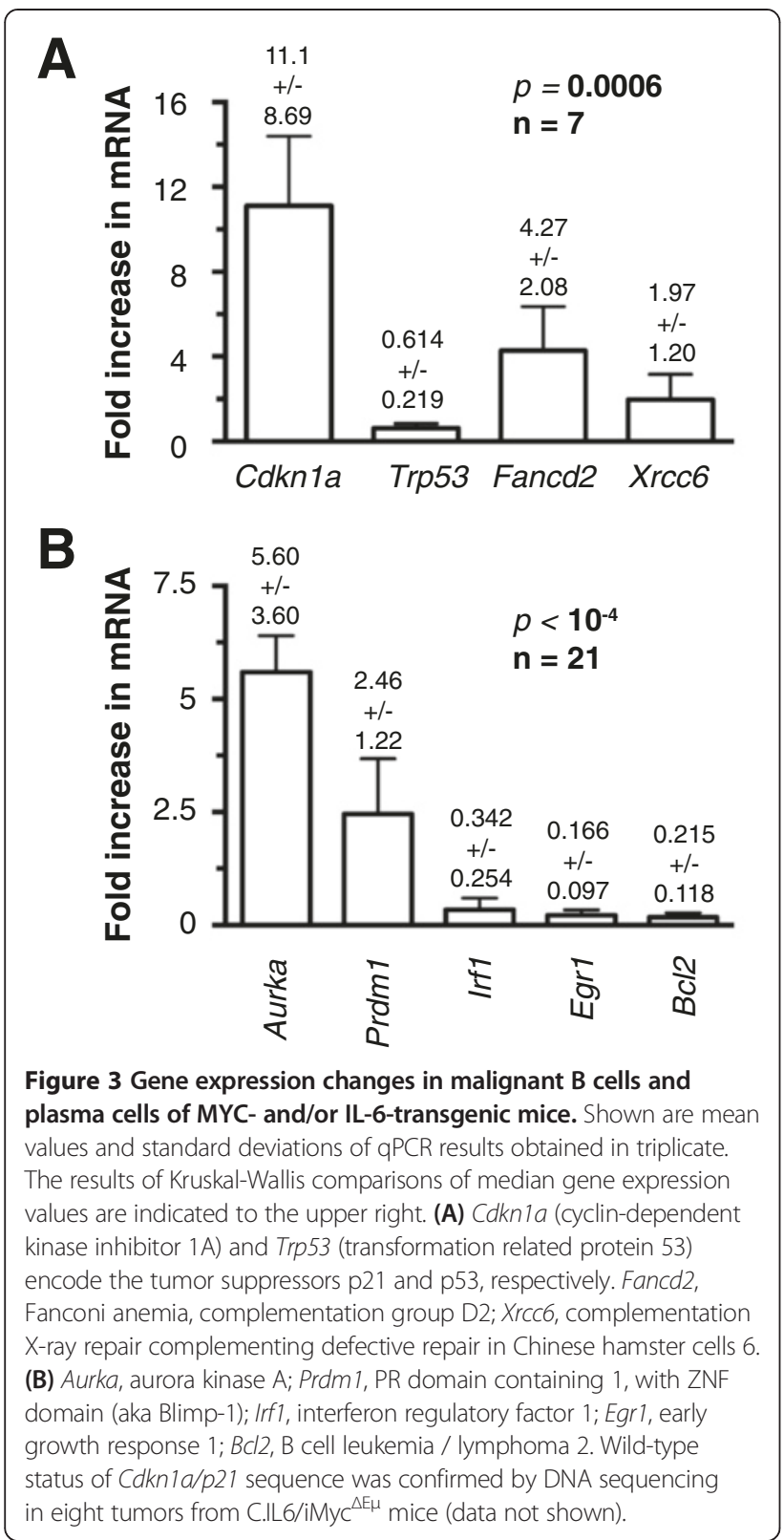

cells (NPCs) from the bone marrow $(81.2 \pm 54.1, \mathrm{n}=22)$ and 1.8-fold higher than in plasma cells from individuals with monoclonal gammopathy of undetermined significance (MGUS; $195 \pm 207, \mathrm{n}=44$ ). Both increases were highly significant using Mann-Whitney analysis $\left(p<10^{-4}\right)$. To test the possibility that FANCD2 expression is of prognostic significance in myeloma, we used the median FANCD2 level in myeloma cells (291 array units) as a cutoff to determine event-free survival (EFS) and overall survival $(\mathrm{OS})$ separately in FANCD2 ${ }^{\text {Low }}$ patients $(\mathrm{n}=175)$ versus FANCD2 ${ }^{\text {High }}$ patients $(\mathrm{n}=176)$. Both EFS $(p=$ $0.004)$ and $O S(p=0.028)$ were significantly shorter in the FANCD2 $2^{\text {High }}$ cohort using log-rank analysis (Figure $5 \mathrm{~B}$ ).
These findings suggested that up-regulation of FANCD2 leads to increased myeloma aggressiveness.

\section{FANCD2 is associated with high-risk myeloma}

Keeping in mind that the prognosis of myeloma depends in large measure on tumor genetics [17] and that risk stratification models of myeloma rely on genetic features, such as changes in gene expression according to the 70gene model [18], to assign newly diagnosed cases to standard-risk groups (median OS $>10$ years) and high-risk groups (2-3 years) [19], we analyzed whether FANCD $2^{\text {High }}$ status might be associated with high-risk disease as defined by the 70-gene signature [18]. Forty-six of 351 myeloma patients $(13 \%)$ carried this signature (Figure $5 \mathrm{C}$ ), with most of them falling into four subgroups of myeloma: proliferation (PR, $n=20$ ), MAF/MAFB (MF, $n=12$ ), MMSET (MS, $\mathrm{n}=9$ ) and hyper-diploid (HY, $\mathrm{n}=4)$. In all four subgroups, mean $F A N C D 2$ levels were elevated in high-risk relative to standard-risk disease, but statistical significance was only reached in one subgroup, PR ( $p=0.0043$, Mann-Whitney test (Figure 5D, left). When all 46 high-risk cases were pooled and the mean FANCD2 expression level of that pool was compared to all 305 standard-risk cases, the up-regulation of FANCD2 in high-risk myeloma was highly significant $(p=0.004$; Figure 5D, right). This result suggested that FANCD2 is a bona fide high-risk myeloma gene as defined by the 70-gene model.

\section{Discussion}

The main finding of this study is the implication of FANCD2 and CDKN1A in high-risk MM and BL, respectively. CDKN1A was first identified as an inhibitor of cell cycle progression and tumor development that is up regulated by wild-type p53 [20,21]. Nowadays CDKN1A is more broadly considered as a regulator of fundamental cell-fate decisions, such as proliferation, differentiation and senescence [22]. With respect to oncogenesis, the tumor suppressor function of CDKN1A is well established, yet there is also growing evidence for oncogenic properties of CDKN1A-encoded p21. For instance, p21 is overexpressed in mouse fibroblasts undergoing transformation induced by ionizing radiation [23]. The underlying mechanism is not known but likely includes protection from apoptosis, which is emerging as key for p21's oncogenic functions [24]. In line with that, cytoplasmic p21, the accumulation of which is stimulated by AKT- or IKK $\beta$ dependent pathways, suppresses programmed cell death [25]. Furthermore, NF-kB-dependent up-regulation of p21 inhibits apoptosis in cells damaged by doxorubicin [26] or UV irradiation [27]. Importantly, tumor development studies in laboratory mice have demonstrated that deletion of Cdkn1a inhibits lymphoma in Trp53-deficient [28], Atm-deficient [29] and normal mice [30], rather than 

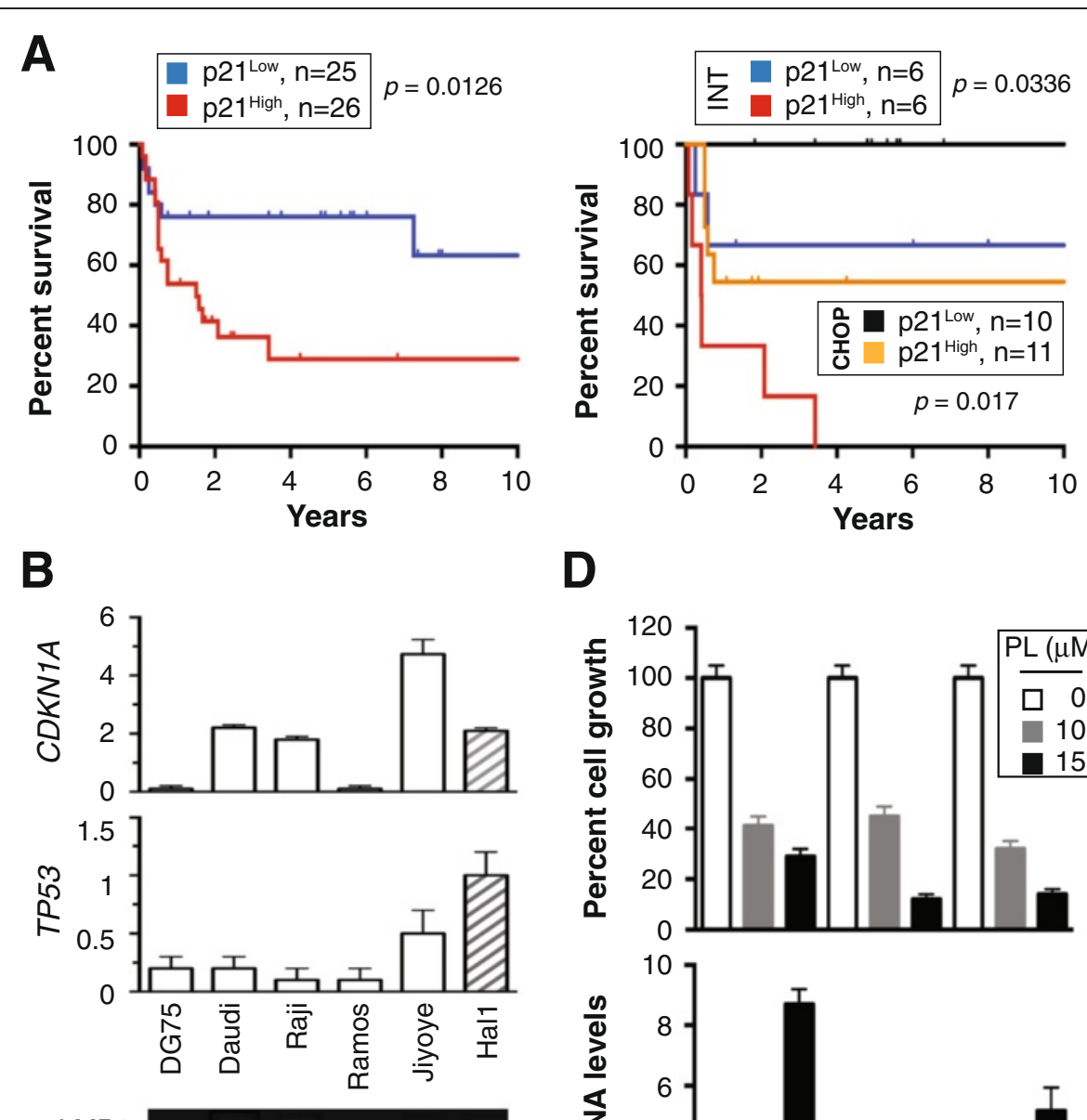

D
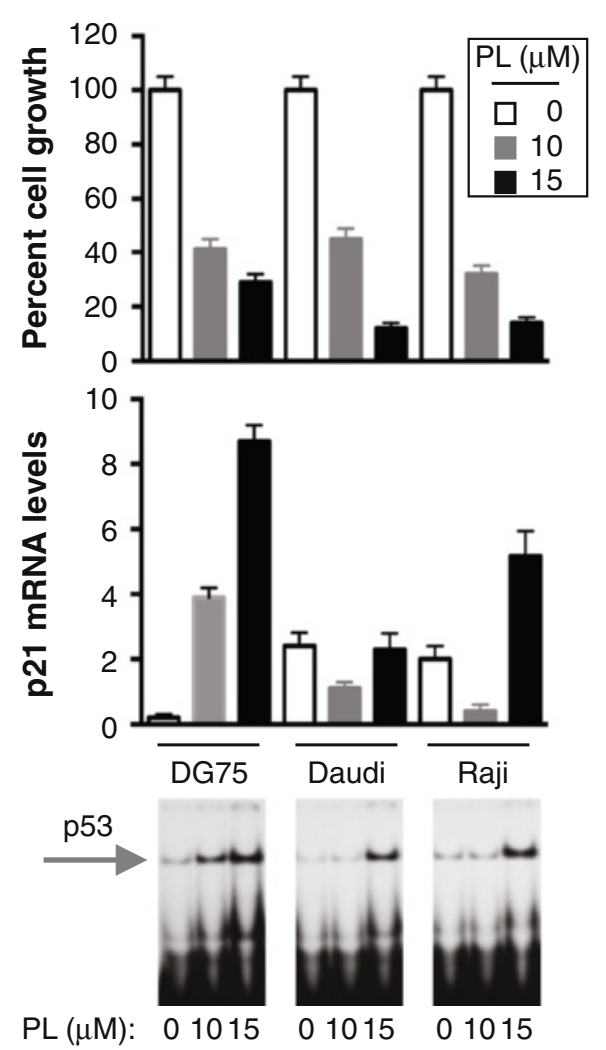

Figure 4 CDKN1A expression prognosticates poor outcome in human BL. (A) Kaplan-Meier curves indicating decreased survival of BL patients expressing high levels of p21 message (Mantel-Cox log-rank analysis). Data are from Dave et al. (GSE4732, probe 202284) [15]. The left panel depicts survival of 51 patients evenly split according to p21 expression into a p21 Low group and a p21 High group. The former demonstrated better outcome $(p=0.0126)$. The right panel shows survival of 33 patients treated with either a CHOP-like regimen or an intensive (INT) drug regimen supplemented in some cases with autologous hematopoietic stem cell transplantation. p2 $1^{\text {Low }}$ patients demonstrated better outcomes than p21 ${ }^{\text {High }}$ patients in both treatment arms. (B) CDKNIA and TP53 expression in 5 human BL cell lines and 1 mouse BL-like cell line, Hal1, derived from a LMP1-transgenic lymphoma. Daudi, Raji and Jiyoye are $\mathrm{EBV}^{+}$and thus express virus-encoded LMP1. DG75 and Ramos are EBV. Because LMP1 activates NF-KB in malignant B cells [43], it is possible that p21 expression in $L M P 1^{+}$cells is driven, in part, by LMP1. (C) EMSA indicating p53 DNA-binding activity in BL and normal B cells. (D) Piperlongumin (PL)-induced activation of the p53-p21 stress response in BL cells. Shown at the top is the growth inhibition of cells upon treatment with $10 \mu \mathrm{M}$ or $15 \mu \mathrm{M}$ PL for 24 hrs (MTS assay). Mean values and error bars, which represent the standard deviation from triplicate experiments, are plotted. The center panel shows the corresponding p21 message levels (qPCR). Differences in both panels were not significant (Mann-Whitney, $p=0.1$ ). Presented at the bottom are the corresponding EMSA results at 24 hrs, indicating that the drug dose-dependent induction of p53 DNA-binding activity was more vigorous at $10 \mu \mathrm{M} \mathrm{PL}$ in EBV ${ }^{-}$DG75 cells compared to EBV ${ }^{+}$Daudi and Raji cells. 


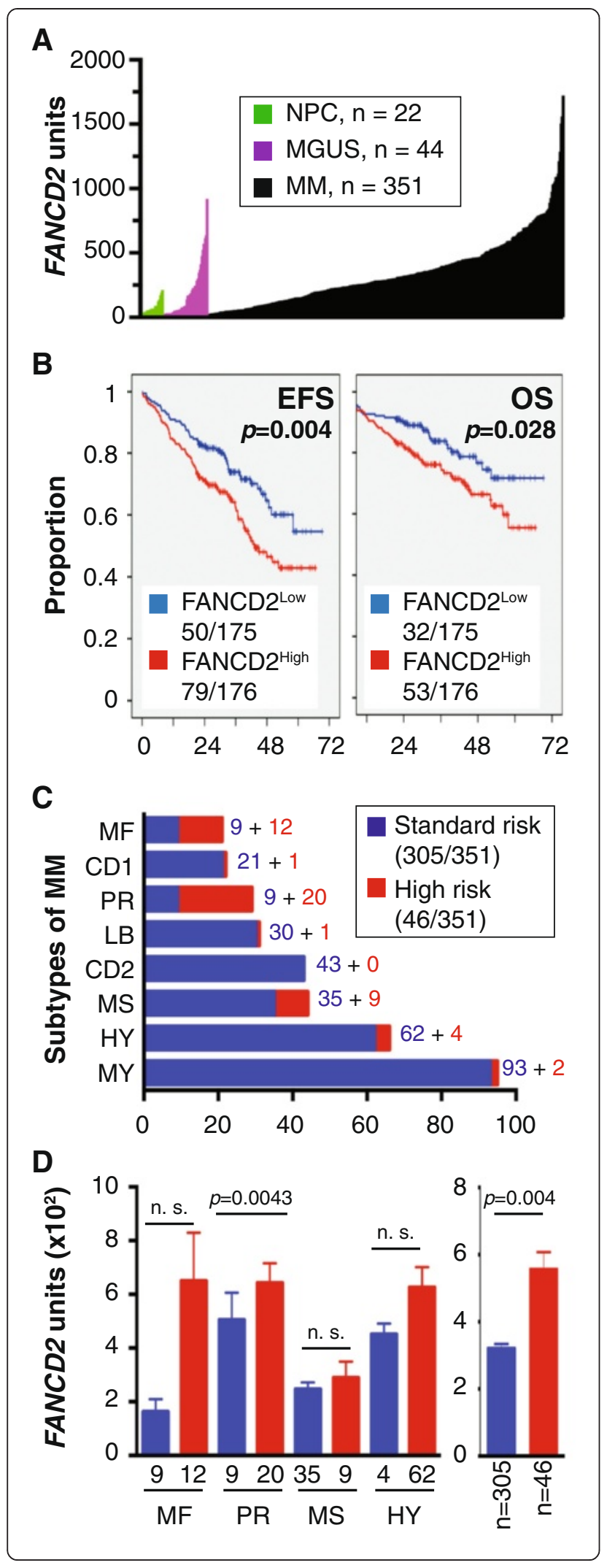

Figure 5 FANCD2 expression predicts poor survival in a subset of patients with newly diagnosed multiple myeloma. (A) FANCD2 mRNA levels (gene probe ID 242560) in normal bone marrow (BM) plasma cells (NPC, green), "premalignant" BM plasma cells from individuals with monoclonal gammopathy of undetermined significance (MGUS, purple) or malignant plasma cells from patients with multiple myeloma (MM, black). (B) Reduced event-free survival (EFS) and overall survival (OS) in myeloma patients with elevated FANCD2 levels (log-rank analysis). Of 351 patients, 175 and 176 patients were arbitrarily categorized as "Low FANCD2" and "High FANCD2," respectively, using the median FANCD2 level in this cohort as cut-off. EFS and OS data were available from 129 (37\%) and 85 (24\%) patients, respectively. (C) Proportion of myelomas ( $n=351$ ) that fell into 8 different subgroups of the disease based on cytogenetic features (e.g., ploidy and chromosomal translocations) and molecular genetic features (e.g., gene expression signatures). From top to bottom, the following subgroups are distinguished: MF, MAF/MAFB; CD1, CCND1/CCND3 group 1; PR, proliferation; LB, low bone disease; CD2, CCND1/CCND3 group 2; MS, MMSET; HY, hyperdiploid; MY, myeloid [39]. The distribution of standard-risk (blue) and high-risk cases (red) according to the 70-gene signature [18] is also indicated. (D) Shown to the left is elevation of FANCD2 message in high-risk myeloma (red) vs. standard-risk myeloma (blue) in 4 of 8 subgroups of the disease included in panel $C$. Mean values (microarray units) and standard error of the mean (SEM) are plotted. Mann-Whitney tests were used for statistical analyses (n. S., not significant). Shown to the right is the increase in FANCD2 mRNA in high-risk disease (red; 13\%) vs. standard-risk disease (blue; 87\%) in 351 myeloma patients. Mean values and SEM are plotted. Median FANCD2 levels in high-risk and standard-risk disease were 473 and 269, respectively.

promoting lymphoma as one might expect from the loss of a tumor suppressor gene. In further agreement with p21's survival-enhancing activity, lymphomas arising in Cdkn1a-deficient mice demonstrate a high rate of apoptosis [31]. In human cancers, overexpression of CDKN1A is frequently seen in carcinoma (prostate, cervix, breast, ovary, skin), brain tumor (glioma) and hematological malignancy [25]. With regard to the latter, strong experimental evidence indicates that p21's pro-survival function plays an important role in the natural history of human leukemia [32]. These findings support the result of this study suggesting that $\mathrm{p} 21$ promotes BL by functioning as an oncogene in the mature B-cell lineage.

The observed overexpression of Fancd2 and Xrcc6 in myeloma-like plasma cell tumors from IL6MYC mice established an interesting parallel to human $\mathrm{MM}$, in which the Fanconi anemia/breast cancer (FA/BRCA) DNA damage repair pathway has been identified as an important effector mechanism of myeloma cell responses to replicative stress induced by DNA alkylating agents, such as the widely used myeloma drug melphalan [33]. FA/BRCA has also been implicated in the acquisition of drug including bortezomib resistance by myeloma cells [34]. FANCD2 is a key player in the FA/BRCA pathway and XRCC6 is a facilitator of DNA double-strand break repair. Both repair proteins are subject to regulation by NF-kB (e.g., p50/RelB dimers) $[33,35,36]$ and both intersect functionally with $\mathrm{p} 21$. The latter is illustrated by reports that $\mathrm{p} 21$ can activate FA-BRCAdependent [37] and XRCC6-dependent [38] DNA repair, 
although this has not yet been demonstrated for myeloma. In this study, we provided clinical evidence for a role of FANCD2 in myeloma. Unlike XRCC6 expression, which was not associated with survival in the Total Therapy 2 (TT2) myeloma dataset used here $(\mathrm{n}=351)$, the message levels of FANCD2 were significantly correlated with eventfree and overall survival of patients with myeloma. Moreover, overexpression of FANCD2 appeared to be a feature of high-risk myeloma, a subset of the disease for which new therapeutic approaches are urgently needed. Patients with high-risk myeloma have extremely poor outcomes; as such, they define an unmet medical need. The median overall survival for patients with standard-risk myeloma is $>10$ years years, yet that for patients with high-risk disease is 23 years, despite the application of aggressive, risk-adapted therapies including tandem autologous stem-cell transplantation (ASCT) and new myeloma drugs [19]. The results presented here support the view that $F A N C D 2$ may be a bone fide high-risk myeloma gene that is worthy for consideration as molecular target for new, targeted therapies of patients with MM.

\section{Conclusion}

Starting with the observation that IL-6 and/or MYCdriven B cell and plasma cell tumors in BALB/c mice exhibit constitutive NF- $\mathrm{kB} / \mathrm{STAT} 3$ activity that leads to up-regulation of NF- $\mathrm{KB}$ target genes, we found that two genes of this sort, CDKN1A and FANCD2, are important for human BL and human MM, respectively. It is possible that these genes drive neoplastic development in the mature B-cell lineage, but this has not been demonstrated here. Additional functional and mechanistic studies are warranted before it can be decided whether CDKN1A and FANCD2 provide viable molecular targets for new therapeutic approaches to BL and MM. MYCdriven BL-like tumors and IL6MYC-driven MM-like tumors in laboratory mice may lend themselves as experimental model systems to that end.

\section{Methods}

Transgenic mice, human BL cell lines, and normal Blymphocytes

The generation and tumor phenotypes of single-transgenic MYC [1] or IL6 [2] mice and double-transgenic IL6MYC mice $[3,4]$ have been previously reported. All transgenes were on the genetic background of BALB/c $(C)$. Breeding, maintenance and handling of mice was conducted according to IACUC guidelines and approved under University of Iowa ACURF study protocol 1301010. Human Burkitt lymphoma (BL) cell lines, purchased from ATCC (Manassas, VA), were maintained in RPMI 1640 supplemented with $10 \%$ heat-inactivated fetal bovine serum, in a humidified $5 \% \mathrm{CO}_{2}$ incubator at $37^{\circ} \mathrm{C}$. Human $\mathrm{B}$ cells were isolated from peripheral blood of healthy individuals as previously described [16]. Normal B220 ${ }^{+} \mathrm{B}$ cells were fractionated from the spleen of inbred $\mathrm{C}$ mice, using $\mathrm{MACS}^{\circ} \mathrm{CD} 45 \mathrm{R}$ magnetic beads columns from Miltenyi Biotec (Auburn, CA).

\section{Quantitative reverse-transcription PCR (qPCR)}

Reverse transcription, performed on $1 \mu \mathrm{g}$ of TRIzol (Sigma-Aldrich, St. Louis, MO)-extracted total RNA, was followed by cDNA synthesis using the AMV reverse transcriptase kit (Roche, Indianapolis, IN). qPCR was performed with the help of TaqMan Universal PCR Master Mix (Applied Biosystems, Carlsbad, CA), using primers and 6-carboxyfluorescein (6-FAM) / Black Hole (BHQ)-labelled probes to specific target genes (IDT, Coralville, IA). Sequences of probes are available upon request. The Applied Biosystems 7900 HT device was used for amplification and detection of PCR product. ABI SDS v 2.3 software (Applied Biosystems, Carlsbad, CA) was employed for analyzing results. The Ct value for each gene was normalized to the internal reference control, HPRT1 for human genes or Hprt for mouse genes, and represented as fold gene expression change relative to gene expression in normal human or mouse $B$ cells or, in case of drug studies, to vehicle-treated cells.

\section{Cell proliferation}

Proliferation was determined using the Cell Titer $96^{\circ}$ MTS/PMS assay (Promega, Madison, WI). Briefly, $1 \mathrm{x}$ $10^{5}$ cells in $100 \mu$ growth media were plated into 96well plates (Costar, Cambridge, MA). After 20 hours, 20 $\mu \mathrm{l}$ of MTS/PMS solution was added per well. Four hours later, the absorbance at $490 \mathrm{~nm}$ was measured using a Multiskan Spectrum plate reader (Thermo Scientific, Hudson, NH).

\section{Preparation of nuclear and cytosolic extracts}

Cells $\left(1 \times 10^{7}\right)$ were lysed with $400 \mu \mathrm{l}$ of buffer A $(10 \mathrm{mM}$ $\mathrm{KCl}, 0.2 \mathrm{mM}$ EDTA, $1.5 \mathrm{mM} \mathrm{MgCl}$, $0.5 \mathrm{mM}$ DTT, and $0.2 \mathrm{mM} \mathrm{PMSF}$ ) at $4{ }^{\circ} \mathrm{C}$ for 10 minutes. Lysate was centrifuged for 5 minutes at 14,000 $g$ and supernatants were collected as cytosolic extracts. Pellet was re-suspended in 100 $\mu \mathrm{l}$ ice-cold buffer $\mathrm{C}$ (20 mM HEPES [pH 7.9], $420 \mathrm{mM}$ $\mathrm{NaCl}, 1.5 \mathrm{mM} \mathrm{MgCl}, 20 \%$ [v/v] glycerol, $0.2 \mathrm{mM}$ EDTA, $0.5 \mathrm{mM}$ DTT, and $0.2 \mathrm{mM}$ PMSF), incubated at $4^{\circ} \mathrm{C}$ for 20 minutes and centrifuged for 6 minutes at $14,000 \mathrm{~g}$. Supernatant was collected as nuclear extract (NE). Protein concentration of NE was determined using a BCA kit (Bio-Rad, Richmond, CA).

\section{Electrophoretic mobility shift assays (EMSA)}

EMSA was carried out in $25 \mu \mathrm{l}$ of binding buffer $(10 \mathrm{mM}$ Tris [pH 7.5], $100 \mathrm{mM} \mathrm{NaCl}, 1 \mathrm{mM}$ DTT, $1 \mathrm{mM}$ EDTA, $4 \%[\mathrm{w} / \mathrm{v}]$ glycerol, $0.1 \mathrm{mg} / \mathrm{ml}$ sonicated salmon sperm DNA), using $10 \mu \mathrm{g}$ of NE. Oligonucleotides containing 
consensus NF- $\kappa B$ (Promega, Madison, WI), MYC/MAX or p53 DNA recognition and binding sites (Santa Cruz Biotechnology, Santa Cruz, CA) were end-labeled to a specific activity of $10^{5} \mathrm{CPM}$, using $\gamma-\left[{ }^{32} \mathrm{P}\right]$-ATP and T4polynucleotide kinase followed by purification on a Nick column (GE Healthcare, Piscataway, NJ). Reaction mixtures were incubated at room temperature for 20 minutes and resolved on $6 \%$ non-denaturing polyacrylamide gels. Gels were dried and subjected to autoradiography. For super-shift assays, $2 \mu \mathrm{g}$ antibody was added ( $20 \mathrm{~min}$, ambient temperature) after the reaction with radiolabeled oligonucleotide had been completed. Antibodies to p50 (sc-114X), p65 (sc-109X), c-Rel (sc-70X), p52 (sc-298X), RelB (sc-48366X) or Myc (sc-764X) were purchased from Santa Cruz Biotechnology (Santa Cruz, CA).

\section{Microarray-based gene expression profiling (GEP)}

GEP using the Affymetrix U133Plus 2.0 microarray (Santa Clara, CA) were performed as previously described [39]. Microarray data and outcome data on the 351 patients included in this study are available in the NIH Gene Expression Omnibus (GEO) under accession number GSE2658. Microarray data on the 44 individuals with MGUS and 22 samples of normal plasma cells (NPC) included here are available at GSE5900. Plasma-cell isolation, total RNA extraction, cRNA synthesis, and hybridization to microarrays were performed as described previously [18]. Statistical analysis of microarray data took advantage of the GCOS1.1 software (Affymetrix, Santa Clara, CA) and involved logrank tests for univariate association with disease-related survival.

\section{Additional file}

Additional file 1: Figure S1. Kaplan-Meier curves showing overall survival of DLBCL patients according to high or low expression of CDKN1A (202284_s_at). Data were mined from Dave et al. (GSE4732) [15]. Vertical hash marks represent a live patient at the indicated follow-up time. Mantel-Cox log-rank analysis was used to compare patient groups (not significant). Survival was recorded for 51 patients according to high and low p21 expression at diagnosis (left). Survival was also plotted for patients treated with either CHOP or a more intensive (INT) regimen (right).

\section{Abbreviations}

BL: Burkitt lymphoma; EBV: Epstein Barr virus; EFS: Event-free survival; EMSA: Electrophoretic mobility shift assay; MM: Multiple myeloma; OS: Overall survival; PL: Piperlongumine.

\section{Competing interests}

The authors declare that they have no competing interests.

\section{Authors' contributions}

SSH and VST performed research, collected and analyzed data, and wrote the paper. DJS, HY, NLK, CLD and CG performed research and assisted in writing the paper. GT and FZ contributed vital insights to data interpretation and wrote the paper. SJ designed and organized research, collected and analyzed data, and wrote the paper. All authors read and approved this manuscript.

\section{Acknowledgments}

This work was supported in part by NIH Training Grant T32-HL07734 and National Natural Science Foundation of China (NNSFC) Grant 81250110552 (both to VT); by a Hyundai Hope on Wheels Research Scholar Grant (to NLK); by NCI R01CA152105, Leukemia \& Lymphoma Society Translational Research Program Awards 6246-11 and 6094-12, and NNSFC Award 81228016 (all to F.Z.); by institutional start-up funds from the Department of Internal Medicine, CCOM, UI (to FZ and GT); by a P50 CA97274 UI/MC Lymphoma SPORE Career Development Award and NCI R01CA151354 (both to SJ); and by $\mathrm{NCl}$ Core Grant P30CA086862 in support of The University of lowa Holden Comprehensive Cancer Center.

\section{Author details}

'Department of Pediatrics, University of lowa Carver College of Medicine, lowa City, IA, USA. '2Department of Pathology, University of lowa Carver College of Medicine, lowa City, IA, USA. ${ }^{3}$ Department of Health and Human Physiology, University of lowa Carver College of Medicine, lowa City, IA, USA. ${ }^{4}$ Department of Internal Medicine, University of lowa Carver College of Medicine, lowa City, IA, USA. ${ }^{5}$ School of Applied Biosciences, Kyungpook National University, Daegu 702-701, South Korea. ${ }^{6}$ Department of Biological Sciences, Hanseo University, Choognam, South Korea.

Received: 7 March 2015 Accepted: 10 March 2015

Published online: 27 March 2015

\section{References}

1. Park SS, Kim JS, Tessarollo L, Owens JD, Peng L, Han SS, et al. Insertion of c-Myc into Igh induces B-cell and plasma-cell neoplasms in mice. Cancer Res. 2005;65(4):1306-15.

2. Kovalchuk AL, Kim JS, Park SS, Coleman AE, Ward JM, Morse 3rd HC, et al. IL-6 transgenic mouse model for extraosseous plasmacytoma. Proc Natl Acad Sci U S A. 2002;99(3):1509-14.

3. Rutsch S, Neppalli VT, Shin DM, DuBois W, Morse 3rd HC, Goldschmidt H, et al. IL-6 and MYC collaborate in plasma cell tumor formation in mice. Blood. 2010;115(9):1746-54.

4. Duncan K, Rosean TR, Tompkins VS, Olivier A, Sompallae R, Zhan F, et al. (18)F-FDG-PET/CT imaging in an IL-6- and MYC-driven mouse model of human multiple myeloma affords objective evaluation of plasma cell tumor progression and therapeutic response to the proteasome inhibitor ixazomib. Blood Cancer J. 2013;3:e165.

5. Han SS, Yun H, Son DJ, Tompkins VS, Peng L, Chung ST, et al. NF-KB/STAT3/ PI3K signaling crosstalk in iMyc ${ }^{\mathrm{E \mu}}$ mu B lymphoma. Mol Cancer. 2010;9:97.

6. Huang WC, Chen CC. Akt phosphorylation of p300 at Ser-1834 is essential for its histone acetyltransferase and transcriptional activity. Mol Cell Biol. 2005;25(15):6592-602.

7. Yuan ZL, Guan YJ, Chatterjee D, Chin YE. Stat3 dimerization regulated by reversible acetylation of a single lysine residue. Science (New York, NY). 2005;307(5707):269-73.

8. Yu Z, Kone BC. The STAT3 DNA-binding domain mediates interaction with NF-kB p65 and inducible nitric oxide synthase transrepression in mesangial cells. J Am Soc Nephrol. 2004;15(3):585-91.

9. Warfel NA, El-Deiry WS. p21WAF1 and tumourigenesis: 20 years after. Curr Opin Oncol. 2013;25(1):52-8.

10. Yook Jl, Kim J. Expression of p21WAF1/CIP1 is unrelated to p53 tumour suppressor gene status in oral squamous cell carcinomas. Oral Oncol. 1998;34(3):198-203.

11. Erber R, Klein W, Andl T, Enders C, Born Al, Conradt C, et al. Aberrant p21 (CIP1/WAF1) protein accumulation in head-and-neck cancer. Int J Cancer. 1997;74(4):383-9.

12. Rey MJ, Fernandez PL, Jares P, Munoz M, Nadal A, Peiro N, et al. p21WAF1/ Cip1 is associated with cyclin D1CCND1 expression and tubular differentiation but is independent of p53 overexpression in human breast carcinoma. J Pathol. 1998;184(3):265-71.

13. Han SS, Tompkins VS, Son DJ, Kamberos NL, Stunz LL, Halwani A, et al. Piperlongumine inhibits LMP1/MYC-dependent mouse B-lymphoma cells. Biochem Biophys Res Commun. 2013;436(4):660-5.

14. Bren GD, Solan NJ, Miyoshi H, Pennington KN, Pobst L, Paya CV. Transcription of the RelB gene is regulated by NF-KB. Oncogene. 2001;20(53):7722-33.

15. Dave SS, Fu K, Wright GW, Lam LT, Kluin P, Boerma EJ, et al. Molecular diagnosis of Burkitt's lymphoma. N Engl J Med. 2006;354(23):2431-42. 
16. Han SS, Son DJ, Yun H, Kamberos NL, Janz S. Piperlongumine inhibits proliferation and survival of Burkitt lymphoma in vitro. Leuk Res. 2013;37(2):146-54.

17. Russell SJ, Rajkumar SV. Multiple myeloma and the road to personalised medicine. Lancet Oncol. 2011;12(7):617-9.

18. Shaughnessy Jr JD, Zhan F, Burington BE, Huang Y, Colla S, Hanamura I, et al. A validated gene expression model of high-risk multiple myeloma is defined by deregulated expression of genes mapping to chromosome 1. Blood. 2007:109(6):2276-84

19. Rajkumar SV. Multiple myeloma: 2012 update on diagnosis, risk-stratification, and management. Am J Hematol. 2012;87(1):78-88.

20. Harper JW, Adami GR, Wei N, Keyomarsi K, Elledge SJ. The p21 Cdkinteracting protein Cip1 is a potent inhibitor of G1 cyclin-dependent kinases. Cell. 1993;75(4):805-16.

21. El-Deiry WS, Tokino T, Velculescu VE, Levy DB, Parsons R, Trent JM, et al. WAF1, a potential mediator of p53 tumor suppression. Cell. 1993;75(4):817-25.

22. Romanov VS, Pospelov VA, Pospelova TV. Cyclin-dependent kinase inhibito p21(Waf1): contemporary view on its role in senescence and oncogenesis. Biochemistry (Mosc). 2012;77(6):575-84.

23. Bhatia K, Fan S, Spangler G, Weintraub M, O'Connor PM, Judde JG, et al. A mutant p21 cyclin-dependent kinase inhibitor isolated from a Burkitt's lymphoma. Cancer Res. 1995;55(7):1431-5.

24. Dotto GP. p21(WAF1/Cip1): more than a break to the cell cycle? Biochim Biophys Acta. 2000;1471(1):M43-56.

25. Abbas T, Dutta A. p21 in cancer: intricate networks and multiple activities. Nat Rev Cancer. 2009;9(6):400-14.

26. Zhou Y, Li G, Ji Y, Liu C, Zhu J, Lu Y. Cytoplasmic p21 induced by p65 prevents doxorubicin-induced cell death in pancreatic carcinoma cell line. J Biomed Sci. 2012;19:15.

27. Basile JR, Eichten A, Zacny V, Munger K. NF-KB-mediated induction of p21(Cip1/ Waf1) by tumor necrosis factor alpha induces growth arrest and cytoprotection in normal human keratinocytes. Mol Cancer Res. 2003;1(4):262-70.

28. De la Cueva E, Garcia-Cao I, Herranz M, Lopez P, Garcia-Palencia P, Flores $\mathrm{JM}$, et al. Tumorigenic activity of p21Waf1/Cip1 in thymic lymphoma. Oncogene. 2006;25(29):4128-32.

29. Wang YA, Elson A, Leder P. Loss of p21 increases sensitivity to ionizing radiation and delays the onset of lymphoma in atm-deficient mice. Proc Natl Acad Sci U S A. 1997;94(26):14590-5.

30. Martin-Caballero J, Flores JM, Garcia-Palencia P, Serrano M. Tumor susceptibility of p21(Waf1/Cip1)-deficient mice. Cancer Res. 2001;61(16):6234-8.

31. Roninson IB. Oncogenic functions of tumour suppressor p21(Waf1/Cip1/ Sdi1): association with cell senescence and tumour-promoting activities of stromal fibroblasts. Cancer Lett. 2002;179(1):1-14.

32. Viale A, De Franco F, Orleth A, Cambiaghi V, Giuliani V, Bossi D, et al. Cell-cycle restriction limits DNA damage and maintains self-renewal of leukaemia stem cells. Nature. 2009;457(7225):51-6.

33. Yarde DN, Oliveira V, Mathews L, Wang X, Villagra A, Boulware D, et al. Targeting the Fanconi anemia/BRCA pathway circumvents drug resistance in multiple myeloma. Cancer Res. 2009;69(24):9367-75.

34. Xiao H, Xiao Q, Zhang K, Zuo X, Shrestha UK. Reversal of multidrug resistance by curcumin through FA/BRCA pathway in multiple myeloma cell line MOLP-2/R. Ann Hematol. 2010;89(4):399-404.

35. Lim JW, Kim H, Kim KH. Expression of Ku70 and Ku80 mediated by NF-KB and cyclooxygenase-2 is related to proliferation of human gastric cancer cells. J Biol Chem. 2002;277(48):46093-100

36. Lim JW, Kim KH, Kim H. NF-kB p65 regulates nuclear translocation of Ku70 via degradation of heat shock cognate protein 70 in pancreatic acinar AR42J cells. Int J Biochem Cell Biol. 2008:40(10):2065-77.

37. Rego MA, Harney JA, Mauro M, Shen M, Howlett NG. Regulation of the activation of the Fanconi anemia pathway by the p21 cyclin-dependent kinase inhibitor. Oncogene. 2012;31(3):366-75.

38. Kumaravel TS, Bharathy K, Kudoh S, Tanaka K, Kamada N. Expression, localization and functional interactions of Ku70 subunit of DNA-PK in peripheral lymphocytes and Nalm-19 cells after irradiation. Int J Radiat Biol. 1998;74(4):481-9.

39. Zhan F, Huang Y, Colla S, Stewart JP, Hanamura I, Gupta S, et al. The molecular classification of multiple myeloma. Blood. 2006;108(6):2020-8.

40. Suematsu S, Matsusaka T, Matsuda T, Ohno S, Miyazaki J, Yamamura K, et al. Generation of plasmacytomas with the chromosomal translocation t(12:15) in interleukin 6 transgenic mice. Proc Natl Acad Sci U S A. 1992;89:232-5.
41. Suematsu S, Matsuda T, Aozasa K, Akira S, Nakano N, Ohno S, et al. IgG1 plasmacytosis in interleukin 6 transgenic mice. Proc Natl AcadSci USA. 1989:86:7547-51

42. Janz S. Myc translocations in B cell and plasma cell neoplasms. DNA Repair (Amst). 2006;5(9-10):1213-24.

43. Shair KH, Bendt KM, Edwards RH, Bedford EC, Nielsen JN, Raab-Traub N. EBV latent membrane protein 1 activates Akt, NFkappaB, and Stat3 in B cell Iymphomas. PLoS Pathog. 2007:3(11):e166.

\section{Submit your next manuscript to BioMed Central and take full advantage of:}

- Convenient online submission

- Thorough peer review

- No space constraints or color figure charges

- Immediate publication on acceptance

- Inclusion in PubMed, CAS, Scopus and Google Scholar

- Research which is freely available for redistribution 